HUMANASE SOCIAIS

V.9 • N.2 • 2021 • Fluxo Contínuo

ISSN Digital: 2316-3801

ISSN Impresso: 2316-3348

DOI: 10.17564/2316-3801.2021v9n2p315-329
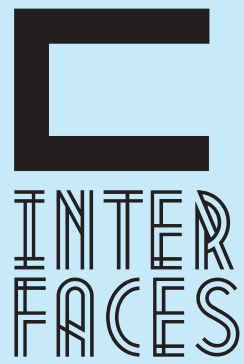

CIENTÍFICAS

\section{CONSIDERAÇÕES ESPARSAS SOBRE PRODUÇÃO DO CUIDADO E REDES DE ATENÇÃO À SAÚDE EM UMA PERSPECTIVA RIZOMÁTICA}

SPARSE CONSIDERATIONS ON CARE PRODUCTION AND HEALTH CARE NETWORKS IN A RHIZOMATIC PERSPECTIVE

CONSIDERACIONES DISPERSAS SOBRELA PRODUCCIÓNDEL CUIDADOY LASREDESDESALUDENUNA PERSPECTIVA RIZOMÁTICA
Francisco Anderson Carvalho de Lima ${ }^{1}$ Diego da Silva Medeiros ${ }^{2}$ João Tadeu de Andrade ${ }^{3}$

\section{RESUMO}

Este texto é fruto de inquietudes emergentes dos processos de pesquisas cartográficas acerca das Redes Temáticas de Atenção à Saúde. Percebe-se a existência de uma rede formalizada, a qual precisa ser garantida e aperfeiçoada enquanto estratégia de política de saúde e aparato do Estado para a garantia da proteção social e dos princípios doutrinários e organizativos do Sistema Único de Saúde (SUS). Há, contudo, a existência de outras redes acessadas pelos trabalhadores e agenciadas pelos usuários. 0 esforço avaliativo das pesquisas demonstrou, por um lado, a problemática da rede formal em apresentar difícil acesso; e, por outro lado, a rede viva, engendrada na produção de vida com acesso facilitado, mas, muitas vezes de pouca resolubilidade. A cartografia, bem como a utilização do usuário-guia para se avaliar as redes e políticas, tem se mostrado como um importante dispositivo de produção de conhecimento em saúde.

\section{PALAVRAS-CHAVE}

Atenção à Saúde. Modelos de Assistência à Saúde. Avaliação em Saúde. Pesquisa Qualitativa. 


\section{ABSTRACT}

This work results of emerging concerns from cartographic research processes on health care networks as a strategy of health policy and state apparatus for the guarantee of social protection and of the doctrinal and organizational principles of Health Unic System (SUS). However there is other networks accessed by workers and brokered by users. The researches evaluative effort showed, on the one hand thematic. It is perceived the existence of a formalized network which needs to be guaranteed and improved, the problem of the formal network which presents difficult access; and, on the other hand, the living network, engendered in the production of life with easy access, but often of little resolubility. The cartography and use of user guide technical to evaluate the networks and policies has been shown as an important device for producing knowledge in health.

\section{KEYWORDS}

Health Care. Healthcare Models. Health Evaluation. Qualitative Research.

\section{RESUMEN}

Este texto es fruto de las inquietudes derivadas de los procesos de investigación cartográfica sobre las Redes Temáticas de Atención de la Salud, se advierte la existencia de una red formalizada, la cual necesita ser garantizada y mejorada como estrategia de política de salud y aparato estatal de salud, garantía de protección social y principios doctrinales y organizativos del Sistema Único de Salud (SUS). Sin embargo, existen otras redes a las que acceden los trabajadores y gestionadas por los usuarios. El esfuerzo evaluativo de las investigaciones demostró, por un lado, el problema de la red formal al presentar dificultades de acceso; y, por otro lado, la red viva, engendrada en la producción de vida de fácil acceso, pero a menudo de escasa resolución. Se ha demostrado que la cartografía, así como el uso de la guía del usuario para evaluar redes y políticas, es un dispositivo importante para la producción de conocimiento en salud.

\section{DESCRIPTORES}

Atención a la salud. Modelos de atención a la salud. Evaluación de la salud. Investigación cualitativa. 


\section{1À GUISA DE INTRODUÇ̃̃O}

Este texto é fruto dos tensionamentos que emergiram no processo de pesquisa compartilhada realizada no município de Fortaleza, Ceará, escrito por uma multiplicidade de mãos. 0 relato compõe os resultados parciais da pesquisa compartilhada Observatório nacional da produção de cuidado em diferentes modalidades à luz do processo de implantação das Redes Temáticas de Atenção à Saúde no SUS: avalia quem pede, quem faz e quem usa, aprovada pelo parecer n ${ }^{\circ} 880.223$ do Comitê de Ética em Pesquisa da Universidade Estadual do Ceará (UECE).

Os questionamentos e inquietudes emergentes impulsionaram a constante conversação entre a prática profissional dos autores e os elementos que surgiram dos encontros promovidos durante a caminhada da pesquisa nos territórios, bem como no processo de (des)territorialização dos pesquisadores, trabalhadores e usuários imersos em movimento ininterrupto.

Deste modo, foram empreendidos esforços no sentido de fornecer uma breve sistematização de elementos que suscitaram constantes discussões no referido processo, tais como: a utilização do dispositivo de construção do usuário-guia (GOMES; MERHY, 2014), este sujeito nômade sobre o qual se dedica o acompanhamento e a operação de sua narrativa como história de vida, trabalhado na contação de sua história e mapeamento do seu território existencial, agenciando algumas linhas que dizem respeito à sua cartografia; a noção de política pública de saúde e as ações em nível de Estado para a garantia de integralidade e acesso universal à saúde; a noção de saúde compreendida pela política e a noção de saúde enquanto imanência e alteridade, a qual corresponde à perspectiva de rede de saúde por uma inspiração rizomática, aberta, conectada e territorializada.

As conversações acerca da implementação das Redes de Atenção à Saúde (RAS) atravessam as discussões nas distintas concepções de saúde. A definição clássica do conceito de saúde da Organização Mundial da Saúde (OMS) preconiza um bem-estar integral e perene, físico, mental e social, esgueirando-se da mera ausência de doença ou condição incapacitante. Porém, no processo de trabalho em saúde, que se dá em ato (FRANCO; MERHY, 2013), encontram-se usuários inseridos em contextos que imanam, por vezes, um processo de (des)construção desse conceito. Os trabalhadores de saúde e gestores também estão imersos neste território vivo de multiplicidade o qual convencionamos chamar de campo da saúde; os elementos enunciados acima são linhas que atuam no processo de subjetivação destas personagens, a saber, os usuários como objeto de ação do cuidado e, os gestores e trabalhadores da saúde como legítimos executores das práticas de cuidado.

Os sujeitos que se encontram na produção do cuidado, sejam usuários ou trabalhadores dos serviços de saúde, não se enquadram em identidades capturáveis. O que tratamos por identidades capturáveis são tipos sociais de fácil reconhecimento e enquadramento na norma. A produção do cuidado lida com sujeitos que são atravessados por uma multiplicidade de intensidades e afetos. 0 estado de saúde descrito no documento da Organização Mundial de Saúde (OMS) não consegue ser aplicado com a mesma vitalidade para todos os sujeitos. Há um meio, um intermezzo, entreato, que é da ordem da relação e do encontro, que, atuando na produção do cuidado, pode afirmar a vida.

A comunidade vulnerável na periferia de uma grande cidade brasileira não produz sujeitos em série com as mesmas características, anseios e atos. As faculdades de saúde, por seu turno, não pro- 
duzem trabalhadores da saúde em série com ele proceder diante do seu ofício. Os sujeitos envoltos neste encontro de produção do cuidado são absolutamente singulares. A compreensão desta máxima auxilia na condução de práticas e manuseio da caixa de ferramentas para o exercício do cuidado. 0 conceito de saúde, assim, sofre um tensionamento, pondo-o em movimento e deslocando-o da posição cômoda assentada em universais abstratos. Afinal, o que é saúde?

Na perspectiva normativa, o acesso dos usuários aos serviços de saúde está condicionado à legislação, tais como, portarias e notas técnicas, que devem ser observadas na prática do cuidado. A produção do cuidado, todavia, transcende a normatização protocolar descrita nos textos legislativos. Uma boa saúde, também, não deve ser medida apenas pela observância protocolar, ou seja, um usuário dos serviços de saúde e um trabalhador que estejam linearmente situados na norma não necessariamente produz vitalidade ou afirmação da vida na produção do cuidado. É possível que uma condição ideal, como preconiza a norma, possa reproduzir práticas de submissão, destrato e violência no cuidado que se exerce.

Franco (2006) aponta que o processo de trabalho, no âmbito de sua micropolítica, desvela um amplo campo de inventividade. E, partindo da experiência vivenciada no cotidiano dos serviços de saúde pelos pesquisadores e trabalhadores, corpos estes que se inscrevem neste texto, entende-se que, por vezes, ainda predomina uma prática de operacionalização do cuidado em saúde a partir de uma definição tradicionalista e moral, refletindo uma vivência fragmentada e voltada para o adoecimento. Ora, sabe-se que a arquitetura do poder se espraia pelos dispositivos sociais, em que se incluem, também, os dispositivos de cuidado em saúde, que autorizam e configuram as práticas discursivas de poder e dominação (FOUCAULT, 2014).

É necessário, portanto, uma reconfiguração da concepção de saúde que operacionalize a prática de cuidado de maneira a amparar-se no processo de trabalho em ato, no encontro vivencial com os usuários em seus territórios existenciais.

Neste sentido, compreende-se que a concepção clássica de adoecimento como ausência de saúde é um conceito fragmentado, incompleto, não se referindo ao processo de saúde em si, mas configurando-se, antes de tudo, como um dispositivo de estratégias políticas interventivas, desligado do trabalho vivo. Essa definição evidenciou um quadro de sujeito-paciente fragmentado, passivo, sem autonomia (COSTA; BERNARDES, 2012).

Diante do exposto a concepção de doença ainda surge como ordenadora do cuidado e da condição epistêmica, uma estratégia que, guardadas as devidas proporções, assemelha-se ao realizado por Pinel ao desacorrentar os loucos em nome do que seria uma humanização do tratamento e acorrentá-los na moralidade da doença mental, reflexo das forças de violação e dominação da sociedade (FOUCAULT, 2016).

Afirma-se, diante disto, que a saúde é uma condição imanente. Isto significa dizer que, operacionalizada para a produção do cuidado, apresenta um caráter processual admitido na produção de vida. A saúde é um movimento de afirmação da vida, por meio das condições de produção de possibilidades, desdobramentos, agenciamentos, processos permanentes de invenção (COSTA; BERNARDES, 2012).

No âmbito do SUS, isto é, no âmbito de política pública, dispositivo jurídico-político do Estado na garantia de direitos orientados para a cidadania, direciona-se a atenção para os determinantes políticos, sociais, históricos e econômicos da política de saúde que respaldam as intervenções em saúde 
no seio do Estado brasileiro. Entende-se, ademais, que a saúde é uma política de proteção social, direito do cidadão e dever do Estado.

Esse processo e seus desdobramentos resultam de embates teóricos e políticos que trazem em seu bojo dificuldades que o setor da saúde enfrentou historicamente. 0 processo de construção do conceito do SUS está conectado com o processo de democratização do estado brasileiro (PAIM, 2017). O qual se encontra na emergência da governamentalidade (arte de governar) neoliberal (FOUCAULT, 2008). O Brasil estava envolto na atmosfera democrática com a iminência das eleições diretas, após duas décadas. Ideias de participação da população em decisões políticas e econômicas foram amplamente disseminadas.

O SUS, portanto, é gerado neste contexto de efervescência política por participação efetiva da população na condução das políticas. Entretanto, em paralelo, o ideário neoliberal, que já havia se inserido nas políticas econômicas da ditadura militar, atuava na concepção individualista e de concorrência, entre indivíduos, para engendrar o progresso social e econômico.

O campo da saúde é atravessado por estas duas perspectivas - participativa e individualista/concorrencial - na prática do cuidado. Dispositivos de participação foram inventados para a esperada atuação dos usuários na condução das políticas públicas em saúde. O Estado, orientado por outro prisma, divulgava a necessidade iminente do enxugamento da máquina pública em nome da racionalização e consequente otimização dos serviços, alimentando a imagem de um Estado mínimo. As duas forças, ainda hoje, repercutem no SUS gerando tensionamentos que o movimentam.

A concepção neoliberal posiciona o indivíduo como absolutamente responsável por sua vida, o sucesso e o fracasso dele é de sua estrita responsabilidade. Este modelo que ganhou força desde o final da década de 1970 produz subjetividade. 0 indivíduo deve, segundo esta teoria, ser empreendedor de si mesmo (OLIVEIRA; SAMPAIO, 2018). A doença ou o desconforto que, eventualmente, acomete os usuários dos serviços de saúde é uma questão pessoal e, por conseguinte, deve ser tratada individualmente. Esta prática ilustra o processo de medicalização da vida, que disciplina e controla os corpos, amparada por conhecimento cientificamente justificado. As RAS estão envoltas nestas relações de força que atuam diretamente na produção do cuidado.

Os elementos que compõem esta cartografia contemporânea estão interligados e se relacionam com as peculiaridades e determinações locais (territorialização), por meio de formas previstas de aproximação de gerência aos cidadãos, seja com descentralização político-administrativa, seja por meio do controle social do sistema. Compreendendo as linhas que estão ativas neste processo de produção de cuidado, o sujeito pode passar de paciente - passivo e objetivado - a usuário cidadão com participação ativa em seu tratamento e cuidado.

\section{UMAS REDES: INTERCONEXÕES E INVENTIVIDADE}

A partir destas ideias, entende-se que há a proposta de operacionalização do cuidado em Redes de Atenção à Saúde (RAS), as quais foram divididas em redes temáticas para se protagonizar grupos e mo- 
dalidades específicas de cuidado. No processo de pesquisa que animou este texto, por exemplo, tem-se o acompanhamento de usuários-guia encontrados a partir da Rede Oncológica e Rede Cegonha.

Os usuários-guia são identificados por um grupo de trabalhadores da saúde e gestores que atuam nas RAS. Os pesquisadores apresentam os objetivos e a metodologia da pesquisa em uma oficina, em seguida, levanta a seguinte questão para o grupo: Quais casos, oriundos das RAS, são consideramos de difícil ou impossível manejo do cuidado? Assim, uma multiplicidade de histórias é narrada no grupo sobre os casos que tensionaram a rede de cuidados.

A partir destas narrativas, algumas histórias são selecionadas de acordo com os objetivos da pesquisa. Estas histórias são tecidas pelo movimento do usuário-guia no território existencial. 0 usuário-guia percorre os serviços de saúde e outros territórios da sua existência, estes espaços fomentam encontros que atuam no processo de afirmação da vida ou, ainda, desvitalização. A pesquisa acompanha este processo de confecção do território existencial com o usuário-guia e o pesquisador que, por seu turno, lança mão do seu corpo como ferramenta de captação das intensidades (GOMES; MERHY, 2014).

Percebe-se que, a partir da experiência de pesquisa e trabalho no SUS, o cuidado do usuário ordena-se em uma perspectiva que escapa à institucionalidade da política pública de saúde. Ora, o usuário é um sujeito nômade, imerso em seu território existencial, imanente, e que agencia a produção do cuidado.

No tocante à rede formal de saúde, de acordo com o Decreto $n^{0} 7.508$, de 28 de junho de 2011 , define-se a RAS como um "conjunto de ações e serviços de saúde articuladas em níveis de complexidade crescente, com a finalidade de garantir a integralidade da assistência à saúde" (BRASIL, 2013, [s.p.]), o que representa a melhora da qualidade da atenção e é diretamente relacionado com os processos e movimentos de regionalização inerentes ao SUS em seus princípios de universalidade, equidade e integralidade, bem como compreendendo os aspectos micropolíticos. É válido ressaltar a necessidade de se empreender esforços para a compreensão e funcionalidade das RAS em territórios e regiões de saúde brasileira.

Neste sentido, a RAS não diz respeito apenas à comunicação entre serviços ou construção de fluxos dos usuários dentro do que os serviços têm a oferecer. Na esteira do entendimento do conceito de saúde enquanto alteridade e imanência, e dos princípios de universalidade, equidade, integralidade, imersos em singularidades do território potencializado e a partir da atuação e existências dos usuários e trabalhadores de saúde, pode-se compreender o funcionamento desta rede. Uma rede com compartilhamento e implicação de uma multiplicidade de atores envolvidos, trabalhadores e usuários, com corresponsabilização e pactuação, voltada não apenas para os serviços, mas, conectada às fragilidades e necessidades destes usuários nos seus territórios existenciais.

O usuário dos serviços de saúde vai tecendo as redes de cuidado a partir do território existencial onde atua e utiliza as ferramentas de que dispõe em mãos para produzir algo que responda ao desconforto. Para tanto, este usuário pratica as redes formais de cuidado, utilizando artifícios que podem burlar a norma e, também, lançam mão de outras redes constituídas por outros sujeitos que não atuem necessariamente nos serviços de saúde. A montagem de uma rede formal de cuidado em saúde bem delineada, com a porta de entrada e todo o seguimento que o usuário deve passar para a prática do cuidado, não garante o controle deste usuário no processo de produção do cuidado. $\mathrm{A}$ 
normatização da rede formal é uma premissa e os próprios gestores e trabalhadores da saúde a reorganizam de acordo com as dinâmicas que a prática induz.

Os sujeitos que atuam na produção do cuidado são redes vivas. As redes vivas são constituídas em ato, fomentadas no encontro entre trabalhadores de saúde e usuários dos serviços de saúde, interagem entre as subjetividades dos sujeitos e vão construindo fluxos que não se territorializam, necessariamente, em um território sedentário, antes segue em movimentos nômades, modificando-se e operando de acordo com o contexto (MERHY et al., 2014). O controle destes fluxos que irrompem na relação com elementos singulares não pode ser enquadrado apenas na observância da norma protocolar, as redes vivas transbordam as análises apressadas.

As questões que emergem ao pensar o cuidado são questões que merecem ser consideradas, potencializadas e operacionalizadas no cotidiano do trabalho, mesmo com as adversidades estruturais e subjetivas que se impõem sobre os trabalhadores. A problematização destas questões irrompe como um instrumento político que potencializa outras ferramentas manejáveis de ação, cunhadas por diferente matriz epistemológica. Isto demonstra a urgência de se reordenar o processo de trabalho e cuidado em saúde, de se compreender a multiplicidade $(n-1)$ do sujeito enquanto usuário, da composição de redes na produção do cuidado.

Reconhecem-se os avanços das RAS enquanto elemento estruturante do SUS. Todavia, ainda há o que aperfeiçoar, considerando as contingências na orientação da produção e gestão do cuidado. Observam-se, ainda, práticas excludentes de intervenções, orientadas por conceitos relacionados à saúde apenas como intervenção sobre a doença e desconhecimento de outras práticas profissionais que não coadunem com o fazer ordinário dos serviços de saúde.

Há o conhecimento dos dispositivos da rede, mas precária acessibilidade dos usuários nestes dispositivos e sem retorno destes encaminhamentos quando acionam outras unidades de saúde para um pretenso cuidado integral; práticas, normas e regras diferentes em cada serviço relacionadas a protocolos de tratamento e encaminhamento que interferem no fluxo; coordenação e gestão voltadas exclusivamente para as unidades de saúde gerando, obstáculos para a conexão entre as RAS; características estas que emergem na prática profissional e que a pesquisa observou no processo de produção dos dados.

Neste sentido, é alvissareira a criação de conceitos que vitalizem os sujeitos protagonistas da produção do cuidado, utilizando ferramentas que se deslocam de um espaço sedentário e que fomente conexões entre as fragilidades das RAS percebidas a partir da experiência e apontamentos dos processos desta pesquisa.

Assim, a partir de um paradigma rizomático e, portanto, que intersecciona, procura-se englobar e agenciar aspectos micropolíticos do cuidado a partir do trabalho vivo em ato, uma vez que é a partir desse prisma que se pode conceber o que é intrínseco ao trabalho (FRANCO, 2006). Este envolve sujeitos a partir de suas práticas de cuidado compreendidas por meio de sua alteridade na relação com o mundo - isto é, saúde como afirmação de vida - a constante transformação subjetiva e política dos diversos atores envolvidos no processo de saúde e cuidado.

A micropolítica, aqui, extrapola os aspectos de adequação a paradigmas pré-estabelecidos e a quaisquer delimitações, posto que o trabalhador seja autogerido e engendrado em um processo de trabalho 
criativo no qual o usuário, em sua relação com o mundo, interfere na alteridade de todos os atores do cuidado (FRANCO, 2015). Isso se dá por meio do processo intersubjetivo que compõe essa rede (muito além das políticas estatais), uma vez que o fio condutor de tensionamento dessas redes é o investimento subjetivo dos envolvidos, já que desobedecer é o único verbo-corpo-alma conhecido pelo rizoma.

Por este motivo, ressalta-se a valorização e empoderamento das redes vivas, redes informais de saúde e cuidado, posto que é justamente neste lugar que se irrompe a promoção da saúde, a partir das ex-sistências, do irromper do vivido. 0 Estado atua aqui a partir das políticas, de maneira a fortalecer tais processos e não os estabelecer, pois não dispõe desse poder.

Convencionou-se tratar a organização das RAS a partir da Atenção Primária à Saúde (APS) como porta de entrada e ordenadora dos fluxos do serviço. O que se vê na prática, contudo, é que o acesso do usuário se dá de diversas maneiras possíveis, justamente porque a sua vivência e o seu corpo não caminham de acordo com a normativa biopolítica empreendida pelo agenciamento clínico proposto pelo Estado em sua política pública.

Assim, entende-se as RAS a partir de uma perspectiva rizomática e por rizoma, grosso modo, entende-se como um sistema conceitual aberto. 0 que significa dizer que se trata de um postulado 0 qual abrange uma cadeia aparentemente oculta, subterrânea, que faz ranger as raízes que sustentam este sistema (DELEUZE; GUATTARI, 2014).

Para tanto, Deleuze e Guattari (2014) lançam mão de princípios para se compreender tal questão e Franco (2006) agencia estes dispositivos teóricos na ótica da produção do cuidado em rede, compreendendo: conexão e heterogeneidade, multiplicidade, ruptura assignificante e cartografia e decalcomania. Tais princípios irrompem um processo de subjetividade, configurado como a resistência empreendida pelo rizoma em desobedecer a tal ordem de reprodução, produzindo antes de tudo. Assim, Deleuze e Guattari (2014) apresentam o rizoma, partindo da botânica e do princípio que na estrutura de algumas plantas, brotos podem brotar em qualquer ponto, assim como engrossar, virando bulbo ou tubérculo, não havendo uma única origem ou raiz.

O foco, pensando na Rede de Atenção à Saúde não seria o serviço ou origem de um encaminhamento, mas as relações, comunicações e teias que envolvem esses serviços de cuidados (FRANCO, 2006). As quais, podem partir de qualquer lugar, sem normas e regras e vão configurando esses caminhos de cuidado. Não há origem, princípios primeiros, lógica, mas uma construção simultânea, a partir de todos os pontos sob a influência de diferentes observações, conceitualizações e comunicações.

\section{A EXPERIMENTAÇÃO CARTOGRÁFICA}

O processo da pesquisa que anima este texto ocorreu em duas capitais do Nordeste brasileiro, Fortaleza e São Luís. Durante dois anos foram acompanhados e mapeados uma variedade de processos de cuidado que tinham como espaço a Rede Cegonha (RC) e a Rede Oncológica (RO). Os mapeamentos destas redes deram origem a várias cartografias e revelou o quanto é singular a produção do cuidado, mesmo que observemos um mesmo equipamento ou até a mesma equipe de saúde.

Interfaces Científicas - Aracaju • V.9 • N.2 • p. 315 - 329 • 2021 - Fluxo Contínuo 
A questão religiosa atravessou a produção cartográfica em vários momentos, tanto na $\mathrm{RC}$ como na RO. A crença na transcendência, personificada na fé dos usuários dos serviços de saúde, atua diretamente na produção do cuidado. Na RC uma gestante vivendo com HIV/AIDS, que conheceu sua sorologia na primeira gestação no ano de 2009, dizia aos profissionais da Unidade Básica de Saúde (UBS), no ano de 2013, que não desejava submeter-se ao tratamento formal preconizado para as infecções pelo vírus HIV porque se achava curada por Deus. A mulher gestante estava assintomática, sem nenhum registro de infecção oportunista neste tempo e não se referia a nenhum desconforto. Ela professava religião protestante e se referia a testemunhos, presenciados em culto e em pesquisas na internet, de pessoas que se curaram da infecção pelo vírus HIV.

A equipe de saúde não sabia como proceder às negativas da mulher em acessar o cuidado proposto pela norma protocolar. 0 desconforto da equipe de saúde era evidente, principalmente pela ironia que a mulher utilizava no trato com os profissionais. Assim, para poder exercer o cuidado, legitimado por norma protocolar, a tática da ameaça da perda de benefícios como o Programa Bolsa Família (BF), caso a usuária não fosse ao serviço, passou a ser ferramenta para forçar a presença da usuária no serviço de saúde. Ameaçava-se com a justificativa de poder exercer o cuidado.

Aos olhos menos atentos, a mulher era refratária ao atendimento por ser uma desviante da norma, no entanto, há uma série de elementos que a observação no processo da pesquisa fez emergir. A mulher tinha verdadeiro pavor de alguém na comunidade conhecer sua condição sorológica, devido ao estigma ainda colado às pessoas que vivem com HIV/AIDS. Desta forma, a ida recorrente à Unidade Básica de Saúde (UBS) ou ao Serviço de Atendimento Especializado (SAE) em HIV/AIDS poderia gerar desconfiança. Aos familiares mais próximos, mais precisamente a família nuclear como o esposo e os filhos, eles não estavam infectados pelo vírus HIV e a vivência na fé protestante e o possível testemunho no templo religioso não se conectava ao cuidado formal previsto para as infecções pelo HIV.

A mulher, uma rede viva, havia construído um mapa de cuidado a partir do seu território existencial. Os trabalhadores de saúde, no entanto, não sabiam destas linhas que atravessavam o corpo desta mulher e desejavam submetê-la à observância da norma protocolar para ofertar um cuidado que fosse legítimo, mesmo que para isso lançassem mão de microfascismos e a desvitalizassem.

Outro mapeamento que realizamos foi o acompanhamento de uma mulher, acometida por transtornos mentais que vivia numa situação de vulnerabilidade social em que a família e o trabalho precário que exercia a desvitalizava. Práticas machistas oriundas do esposo e da sogra e a situação de penúria aprofundavam a depressão e o pânico que a acometiam. A mulher foi atendida pelo Centro de Atenção Psicossocial (CAPS), foram administradas medicações que amenizassem o sofrimento psíquico, mas o estado depressivo ainda se aprofundava. A morte de um sobrinho que a auxiliava no trabalho a deixou em situação de muita dificuldade, sem perspectiva para a produção do cuidado.

Adiante, esta mulher foi diagnosticada com câncer de mama. Ela iniciou o tratamento no hospital filantrópico referência do estado. Inicialmente possuía limitações que imprimia obstáculos ao cuidado, pois, havia certo pânico aos profissionais de saúde que trajassem jaleco. Assim, a usuária fugia ao mero sinal da presença do traje dentro do hospital e sabe-se a quantidade de jalecos presentes em uma unidade de saúde. A equipe tinha uma ferramenta para o cuidado oncológico: um grupo de 
mulheres que haviam passado pela experiência e que socializam suas histórias. A usuária, então, passou a frequentar o grupo.

A vivência neste grupo mudou radicalmente a postura da usuária que passou a se vitalizar e afirmar a vida mesmo em situações adversas. Associado ao cuidado formal nos casos de neoplasia mamária, a troca de experiências no grupo de mulheres que viviam ou viveram a mesma situação a vitalizava. O medo do jaleco branco passou, recebendo inclusive seu próprio jaleco quando passou a ser voluntária do projeto. As investidas agressivas dos familiares e comunidade já não a afetavam de forma negativa. A depressão já não a paralisava, passou a cuidar de si e a gostar do seu próprio corpo. A produção do cuidado possui elementos singulares que somente no encontro é possível dispô-los.

Em outra situação, houve a cartografia de um usuário-guia diagnosticado com câncer de pâncreas. Este sujeito gozava do arquétipo do macho, exercendo domínio sobre as diversas mulheres que faziam parte de sua rede de existência. Praticou de violência física e psicológica contra todas as companheiras que passaram por sua vida e ao se dirigir às mulheres utilizava-se de fala imperativa.

Encontrava-se agenciado ao machismo e ao patriarcalismo. Por um lado, isso reverberou em todo o seu histórico de cuidado, pois nunca havia frequentado serviços de saúde até a crise. Não faz sua própria comida, nem corta as próprias unhas, nem os cabelos, o que fica sob responsabilidade de sua ex-companheira, que ainda reside próximo, e da atual.

Por outro lado, tais características, junto à sua invenção de redes de cuidado forneceram elementos relevantes no seu processo de enfrentamento ao adoecimento, tais como a reaproximação com a filha; a mudança no tratamento com as mulheres, tornando-o mais carinhoso; e uma vivacidade própria que postergou o agravamento do câncer. Ao passo que se mostrava um corpo orgânico aos poucos se fragilizando, expandia-se a sua inventividade, pois o usuário foi levado a buscar estratégias familiares de fortalecimento e mudança em suas relações com as pessoas que o cercam, todas mulheres.

A sua filha é profissional do hospital de referência e, após anos sem falar com ele, mesmo morando no mesmo quarteirão, reassume os laços com o pai e se responsabiliza pela condução do seu tratamento, facilitando o acesso à rede formal. A mãe da profissional, apesar de temer a reaproximação com o usuário-guia, vez em quando lhe enviava marmitas com almoço e jantar.

Todos estes elementos e mais alguns só foram percebidos e discutidos com os atores de todo o processo de pesquisa a partir da micropolítica e territorialização. Os aspectos de machismo e patriarcalismo foram operacionalizados na ótica do cuidado em rede e de maneira imanente, a partir de uma rede de cuidado engendrada em um território existencial.

A partir dessas breves ilustrações vemos a potencialidade do encontro como ferramenta de pesquisa e cuidado, bem como a materialização das redes vivas em suplementação das redes formais. Afirmamos, com isso, a compreensão rizomática das redes de cuidado. Contudo, mediar, costurar, preencher os espaços vazios dentro desta construção de redes, onde se possibilite o fluxo e o acesso a uma rede de atenção e cuidados, sem perder de vista o usuário é o grande desafio.

Ora, a espontaneidade, uma acolhida processual e de qualidade, orientada para uma clínica operacionalizada pela noção de saúde enquanto alteridade e imanência, em qualquer ponto da rede, com vínculos construídos e estabelecidos, implicação e pactuação, confiança, fazem com que seja

Interfaces Científicas - Aracaju • V.9 • N.2 • p. 315 - $329 \cdot 2021$ - Fluxo Contínuo 
construída toda uma linha de cuidados compartilhados. Uma clínica, processo de trabalho vivo em ato, que considere um corpo que se expande na imanência, a produção de subjetividade existente nos agenciamentos de cuidado, uma clínica dos afetos (FRANCO; GALAVOTE, 2010).

Isto fortalece o usuário em sua rede viva, em sua produção do cuidado, configura o campo de práticas e do cuidado de si, por meio de um papel ativo, necessário, no contexto de seu tratamento e que respeita e considera o seu território existencial, sua singularidade (n-1). Fala-se aqui de uma rede de cuidados em conjunto, com implicação dos diversos atores que a atravessam, que não necessita de origem, fim, ou estrutura primeira. Esta rede, portanto, existe no fluxo, nas relações, comunicações dos dispositivos com o usuário.

Ademais, agenciar espaços para a comunicação dos trabalhadores dentro dos serviços é potente, pode estimular a inventividade. Neste sentido, há o reconhecimento que apenas um saber, um serviço, é insuficiente. A rede é um dispositivo constituído de vários atores. $\mathrm{E}$ o reconhecimento do usuário, como um ator deste cuidado, é imprescindível para se falar em cuidado em rede.

A partir das considerações elaboradas neste texto pode-se empreender a perspectiva do que se entende enquanto rede e que, de acordo com a visão ora apresentada, consegue abranger questões que não são contempladas pela lógica biomédica tradicional no desenho das RAS.

O rizoma compreende o próprio fluxo da história e da subjetividade relacional que se produz em ato, podemos dizer que isto significa afirmar que os usuários narram, significam, enfim, vivem, de acordo com um movimento rizomático e, por conseguinte, adentram a RAS a partir de qualquer ponto, o qual é conectado e singular na rede de existência do usuário. Por mais que se pontue e trate a Atenção Primária como porta de entrada e ordenadora do fluxo o que acontece na prática não corresponde a este protocolo, apesar da noção de que acompanhando esta normativa a rede formal poderia seguir seu fluxo proposto pela política pública e talvez garantir a integralidade.

Levanta-se, contudo, as seguintes questões: é a realidade vivencial das pessoas em situação de cuidado com seus agenciamentos que devem adequar-se à política pública ou o contrário? Seria o esforço do estado em ordenar o fluxo de serviço uma maneira de exercer domínio sobre o corpo? 0 que é importante nestas reflexões é a quebra com a lógica de dominação do corpo pelo estado e a compreensão dos agenciamentos envolvidos na existência dos usuários que buscam o cuidado.

Somente com a característica da multiplicidade pode-se considerar o sujeito (n-1) e dar conta de sua realidade de maneira ampla a partir de sua singularidade, bem como no trabalho em ato. A RAS pode ser rompida sem necessariamente ser descaracterizada em sua função de cuidar e garantir a integralidade - é notório que durante o tratamento o usuário percorre as diversas redes de cuidado formal. A análise de uma RAS não compreende apenas a si mesma, mas sim a todo o SUS, já que a política pública funciona na garantia de atenção integral ao usuário.

A partir da cartografia das existências dos usuários em seus agenciamentos, isto é, em suma, em sua própria experiência de vida, podem-se mapear as conexões existentes na realidade vivida, em que a produção de subjetividade irrompe, ilustrando o funcionamento da produção do cuidado, posto que na prática observa-se que a mera protocolação dos serviços não garante um cuidado eficiente e digno e que respeite os preceitos do SUS. 
Ademais, convém a reafirmação da perspectiva de rede viva, que compreende a multiplicidade de sentidos que fundamentam a existência de um sujeito, isto é, como seu corpo afetivo relaciona-se com o mundo, promovendo e buscando cuidado num sistema existencial e vivo que transcende o serviço formal de saúde, o que é elemento singular para a discussão empreendida a partir deste texto.

\section{ALGUMAS CONSIDERAÇÕES [OU CONSIDERAÇÕES ESPARSAS]}

Este texto não pretendeu esgotar a discussão ou apresentar respostas prontas às problemáticas elencadas, as quais emergiram a partir da experiência profissional e de pesquisa dos autores e da composição de sujeitos no processo de execução da pesquisa.

Infere-se, contudo, a necessidade de se alargar a compreensão acerca dos conceitos de saúde que operacionalizam a formação e as práticas profissionais, a organização dos serviços e a implementação da política pública de saúde brasileira. Isto se deu a partir de inquietações vivenciadas nos territórios dos diversos atores envolvidos no processo a partir da composição de redes temáticas de atenção à saúde no município de Fortaleza.

As conversações sobre os processos de trabalho, os quais, como se sabe, são autogeridos, precisam ser fomentadas e realizadas constantemente no cotidiano dos serviços e no desenvolvimento de pesquisas e estudos. A cartografia, bem como a utilização do usuário-guia para se avaliar as redes e políticas, tem se mostrado como um importante dispositivo de produção de conhecimento em saúde.

Percebe-se a existência de uma rede formalizada, a qual precisa ser garantida e aperfeiçoada enquanto estratégia de política de saúde e aparato do Estado para a garantia da proteção social e dos princípios doutrinários e organizativos do SUS. Há, porém, a existência de outras redes informais, redes mais acessíveis que trabalhadores utilizam informalmente e outra rede que os usuários trazem e que muitas vezes não é percebida pelos trabalhadores de saúde e pesquisadores, agenciada pelo usuário em seu processo de existência, circunscrita no território e nas relações sociais como um todo, as quais podem ser também as próprias relações familiares, comunitárias, sociais e laborais.

Com relação a isso, a pesquisa demonstrou, por um lado, a problemática da rede formal, em geral, apresentar difícil acesso ao usuário com diversas normas enrijecidas de perfil, acolhimento, vínculo, responsabilização e encaminhamento; e, por outro lado, a rede viva do usuário, engendrada na sua produção de vida com acesso facilitado, mas, muitas vezes de pouca resolubilidade.

Diante disto, admitem-se os desafios para o exercício da saúde coletiva e dos processos de trabalho em si e a necessidade de articulação contínua entre as redes denominadas rizomáticas, na produção do cuidado, o que se dá por meio da conversação entre os diversos atores envolvidos no processo de cuidado, formando uma rede propositiva, uma clínica que ande ao lado do usuário, nem à frente, nem atrás, que não o guie, e que seja instrumento de afirmação da vida e vitalidade.

Interfaces Científicas • Aracaju • V.9 - N.2 • p. 315 - 329 • 2021 - Fluxo Contínuo 


\section{REFERÊNCIAS}

BRASIL. Ministério da Saúde. Secretaria de Gestão Estratégica e Participativa. Decreto n0 7.508, de 28 de junho de 2001, regulamentação da Lei nº 8.080/90. 4. reimpr. Brasília: Ministério da Saúde, 2013.

COSTA, Márcio Luis; BERNARDES, Anita Guazzelli. Produção de saúde como afirmação de vida.

Saúde e Sociedade, São Paulo, v. 21, n. 4, p. 822-835, 2012. Disponível em: https://www.scielo.br/ pdf/sausoc/v21n4/v21n4a03.pdf. Acesso em: 3 jul. 2020.

DELEUZE, Gilles; GUATTARI, Felix. Mil platôs: capitalismo e esquizofrenia 2, v. 1. 2. ed. São Paulo: Editora 34, 2014.

GOMES, Maria Paula Cerqueira; MERHY, Emerson Elias. Pesquisadores IN-MUNDO: um estudo da produção do acesso e barreiras de saúde mental. Porto Alegre: Rede Unida, 2014.

FOUCAULT, Michel. História da loucura na idade clássica. 8. ed. Rio de Janeiro: Perspectiva, 2016.

FOUCAULT, Michel. Microfísica do poder. 28. ed. Rio de Janeiro: Paz e Terra, 2014.

FOUCAULT, Michel. Nascimento da biopolítica. São Paulo: Martins Fontes, 2008.

FRANCO, Túlio Batista. As redes na micropolítica do processo de trabalho em saúde. In: PINHEIRO, Roseni; MATTOS, Ruben Araújo de (org.). Gestão em redes. Rio de Janeiro: CEPESC-IMS/UERJLAPPIS, 2006. p. 459-473.

FRANCO, Túlio Batista; GALAVOTE, Heletícia Scabelo. Em busca da clínica dos afetos. In: FRANCO, Túlio Batista; RAMOS, Valéria do Carmo (org.). Semiótica, afecção e cuidado em saúde. São Paulo: Hucitec, 2010. p. 176-199.

FRANCO, Túlio Batista. Trabalho criativo e cuidado em saúde: um debate a partir dos conceitos de servidão e liberdade. Saúde e sociedade, São Paulo, v. 24, suppl. 1, p. 102-114, 2015. Disponível em: https://www.scielo.br/pdf/sausoc/v24s1/0104-1290-sausoc-24-s1-00102.pdf. Acesso em: 3 jul. 2020.

FRANCO, Túlio Batista; MERHY, Emerson Elias. Trabalho, produção do cuidado e subjetividade em saúde: textos reunidos. São Paulo: Hucitec, 2013.

MERHY, Emerson Elias et al. Redes vivas: multiplicidades girando as existências, sinais da rua. Implicações para a produção do cuidado e a produção do conhecimento em saúde. Divulgação em Saúde Para Debate, Rio de Janeiro, v. 52, p. 153-164, 2014. 
OLIVEIRA, Robson; SAMPAIO, Simone Sobral. Neoliberalismo e biopoder: o indivíduo como empresa de si mesmo. Textos \& Contextos, Porto Alegre, v. 17, n. 1, p. 167-177, jan./jul. 2018. Disponível em: http://revistaseletronicas.pucrs.br/fass/ojs/index.php/fass/article/download/23483/17160. Acesso em: 3 jul. 2020.

PAIM, Jairnilson Silva. Reflexiones teóricas sobre sujetos de la práxis y sujetos de la antítesis para la Reforma Sanitaria Brasileña. Salud Colectiva, Lanús, v. 13, n. 4, p. 599-610, 2017. Disponível em: https://www.scielosp.org/article/scol/2017.v13n4/599-610. Acesso em: 3 jul. 2020. 
1 Mestre em Avaliação de Políticas Públicas, Universidade Federal do Ceará - UFCE; Especialista em Saúde Coletiva - Escola de Saúde Pública do Ceará; Especialista em Saúde Mental - Universidade Estadual do Ceará UECE; Bacharel em Psicologia - Universidade Estadual do Ceará. E-mail: acarvalho.eco@gmail.com

2 Mestre em Saúde Coletiva, Universidade Estadual do Ceará UECE; Especialista em Saúde Pública - Escola de Saúde Pública do Ceará; Licenciado em Ciências Sociais Universidade Estadual do Ceará - UFCE.

E-mail: diegosmedeiros@gmail.com

3 Doutor em Antropologia - Universidade Federal da Bahia - UFBA; Mestre em Sociologia - Universidade de Brasília UNB; Bacharel em Ciências Sociais, Universidade Federal do Ceará -UFCE; Professor Associado do Departamento de Ciências Sociais e Programa de Pós-graduação em Sociologia da Universidade Estadual do Ceará - UECE.

E-mail: joao.andrade@uece.br

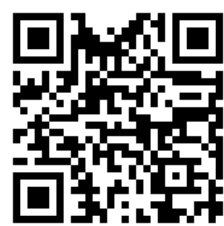

A autenticidade desse artigo pode ser conferida no site https://periodicos. set.edu.br

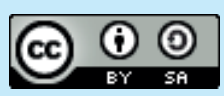

Este artigo é licenciado na modalidade acesso abertosob a Atribuição-Compartilhalgual CC BY-SA

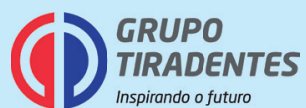

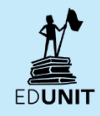

